\title{
The role of public procurement in the formation of markets for innovation
}

DOI:

10.1016/j.jbusres.2018.11.032

\section{Document Version}

Accepted author manuscript

Link to publication record in Manchester Research Explorer

\section{Citation for published version (APA):}

Bleda, M., \& Chicot, J. (2019). The role of public procurement in the formation of markets for innovation. Journal of Business Research, 107, 186-196. https://doi.org/10.1016/j.jbusres.2018.11.032

\section{Published in:}

Journal of Business Research

\section{Citing this paper}

Please note that where the full-text provided on Manchester Research Explorer is the Author Accepted Manuscript or Proof version this may differ from the final Published version. If citing, it is advised that you check and use the publisher's definitive version.

\section{General rights}

Copyright and moral rights for the publications made accessible in the Research Explorer are retained by the authors and/or other copyright owners and it is a condition of accessing publications that users recognise and abide by the legal requirements associated with these rights.

\section{Takedown policy}

If you believe that this document breaches copyright please refer to the University of Manchester's Takedown Procedures [http://man.ac.uk/04Y6Bo] or contact uml.scholarlycommunications@manchester.ac.uk providing relevant details, so we can investigate your claim.

\section{OPEN ACCESS}




\title{
The role of public procurement in the formation of markets for innovation
}

\author{
Mercedes Bleda \\ Alliance Manchester Business School \\ University of Manchester \\ Mercedes.bleda@manchester.ac.uk \\ Julien Chicot \\ Joint Institute for Innovation Policy (JIIP) \\ Julien.e.j.chicot@posteo.net
}

\begin{abstract}
In this work we analyze the ways in which public procurement can encourage business innovation by supporting the formation of markets for new products, technologies and services. We use an evolutionary analytical framework in which markets for innovation are defined as dynamic complex systems whose function is the creation and coordination of knowledge as they develop over time. We show that public procurement has a key role in supporting this function throughout all the stages in the process of market development, and identify specific tools and actions that can be implemented at different phases of the procurement cycle to do so. We illustrate the main conceptual arguments of our analysis with examples from existing case studies on the public procurement of innovations.
\end{abstract}

Keywords: innovation, public procurement, markets as complex systems, evolutionary market formation, knowledge coordination 


\section{Introduction}

Public procurement $(\mathrm{PP})$ is recognised in the literature on innovation policy as one of the most direct forms of encouraging innovation (Brammer and Walker, 2011; Edler and Georghiou, 2007; European Commission, 2007; 2011; Geroski, 1990). PP is the acquisition of goods and services by a government or a public sector organization (Uyarra, 2010; Roflstam, 2013). By demanding and purchasing innovative solutions to address unmet needs and social challenges, public organizations can encourage private businesses to mobilise the creativity and resources required to develop them (Tsipouri, 2015). Public demand can be thus be targeted and PP designed to stimulate innovation ${ }^{1}$ by influencing the markets for specific new products, technologies, and services (Edler et al, 2005; Rosthwell, 1984).

The ways in which PP can influence the market have been discussed in the innovation literature mostly within two perspectives. One perspective considers that PP can contribute to the wellfunctioning of markets for innovations by addressing information related 'market failures', i.e. deficiencies and asymmetries in the information available to those intending to undertake or to purchase innovations (Edler and Georghiou, 2007; Georghiou et al, 2014). In this informationbased view, markets are conceived as pre-existing or 'given' (Mele et al., 2015; Vargo et al., 2017), and the role of PP is to help making sure that they work adequately. As a result, analyses within this perspective do not incorporate explanations of how markets are created (Aspers, 2011), how they develop over time (Buzzell, 1999), or how PP can support innovation by facilitating these processes.

A second perspective within innovation studies has moved away from this information-based view and emphasised the importance of knowledge and interactive learning in markets in the

\footnotetext{
${ }^{1}$ Innovation is the development and diffusion of new products (goods or services) or processes, as well as the creation of new organizational methods and set-ups (Dosi, 1988; OECD, Eurostat 2005). In our context, public organizations can contribute to innovation by influencing the market in two ways: by demanding and purchasing completely new-to-the-world products and/or services, or products and/or services that are new in the country (or region) so innovation is required in order to adapt them to the specific national or local context.
} 
context of innovation (Edler and Georghiou, 2007; Edler et al, 2005; Hommen and Rolfstam, 2008; Rolfstam, 2013). In addition to emphasise the importance of knowledge as fundamentally different from information, this perspective also considers that markets are seldom, if ever, simply 'given' (Edler et al, 2005; p. 18): they need to be created and they change as they develop over time. Analyses within this knowledge-based perspective therefore suggest a more realistic and dynamic view of what markets for innovation are and how they function; they however fail to elaborate and apply this view to provide explanations of how PP can help the market development process. While acknowledging that markets for innovations are dynamic, and that knowledge matters in this dynamics, this body of work does not provide an account of the specific ways in which PP can support knowledge coordination at the different stages through which a market for an innovation develops. Existing work also tends to focus on the role of PP at the early phases of market creation overlooking its effects in later stages and the dynamic interactions and potential feedbacks between them. In addition, these analyses do not identify the specific PP instruments and actions that can be implemented at each phase of the procurement cycle to facilitate all market developmental stages.

In this paper, we present a conceptual elaboration of this knowledge-based perspective of the role of PP in markets for innovation in order to address its limitations. More specifically, we analyse how PP can support the formation of markets at their different interrelated stages of development, and identify PP actions and instruments that can be implemented at different points of the procurement cycle to do so. In order to capture the dynamic and knowledge related nature of markets, we use the evolutionary analytical framework proposed by Dopfer and Potts (2008) and adapted to the case of markets for innovations by Bleda and del Rio (2013). In this framework, markets are defined as dynamic complex systems whose main function is the creation and coordination of knowledge (Metcalfe, 2005; Potts, 2001). As dynamic systems, markets are not pre-existing or 'given' but form over a three-stage developmental trajectory 
that is underpinned by three distinctive processes of knowledge creation and coordination (Bleda and del Río, 2013). Our conceptual elaboration uses this theoretical framework and analyzes how PP can support market formation by facilitating these three knowledge coordination processes at different points of the procurement cycle.

To illustrate the main conceptual arguments of our analysis we use empirical evidence from selected existing case studies from the literature on PP of innovation. Our selected cases thus constitute a purposive sample (Droste et al., 2016; Yin, 2011) aimed at illustrating the key ideas of our conceptual elaboration. Theoretical developments that are built with reference only to theory run the danger of becoming too abstract and out-of-touch with reality. Using case data as illustration allows to establish a closer link between conceptual elaborations and the theoretical constructs used to build them, making their key arguments more powerful and persuasive (Siggelkow, 2007). The ability to get closer to theoretical constructs is particularly important in research like ours that tries to unravel the underlying dynamics of phenomena that play out over time (ibid, p.3). Providing a concrete example of the constructs that we have used in our theoretical analysis contributes to a better understanding of our conceptual arguments, and of how they might actually be applied to empirical settings (Siggelkow, 2007). ${ }^{2}$

The paper is organised as follows. In Section 2 we present an overview of how the role of PP in supporting markets for innovation has been discussed in the existing literature. In Section 3 we present the concept of the market and its dynamic formation process within our chosen evolutionary framework. Section 4 presents our case selection criteria, the basic characteristics of the selected case studies, and our method for information and evidence coding. In Section 5

\footnotetext{
2 Using case data as illustration is an adequate method only if the conceptual development is 'free-standing', i.e. its arguments are plausible and internally logic, so the sequence followed in theoretical work that uses case data as illustrations is generally to present the conceptual arguments of the analysis and then the examples (Siggelkow, 2007). We follow this sequence and present first our main conceptual arguments which we formulate as propositions, and then provide examples from our selected case studies to illustrate them.
} 
we analyse the ways in which PP can support market formation at different points of the procurement cycle, presenting our main conceptual arguments in the form of propositions and providing examples from our selected cases. Section 6 concludes and presents the limitations of our analysis.

\section{Public procurement and markets for innovations}

Despite its importance, the market context has been 'a neglected dimension of studies of PP of innovation, one that has been paid relatively little, or else rather inconsistent, attention in much of the previous literature' (Edler et al., 2005; p. 18). Only a few existing analyses have discussed the role of PP in markets for innovation mainly within two perspectives. In the first perspective, rooted in standard neoclassical economics, markets are conceived as pre-existing or given entities whose main function is the (efficient) allocation and coordination of resources and information (Vargo et al., 2017). In this view, knowledge is conceived as equivalent to information, and so the market function is to coordinate information (as an input) and allocate resources for the production and distribution of new knowledge (as an output) also understood as information (Potts, 2001; Smith, 2000). Problems hindering the well-functioning of markets for innovation are thus information related asymmetries or 'market failures' that can be corrected via government intervention (Arrow, 1962; Nelson, 1959). The role of PP in this view is thus help assuring the well-functioning of an existing market (Hviid and Price, 2014; Saussier and Tirole, 2015) by addressing deficiencies and asymmetries in the information available to those intending to undertake or to purchase innovations (Chicot and Matt, 2018; Edler and Georghiou, 2007). In this static information-based setting, once PP helps solving these deficiencies, and the market works efficiently, customers are 'best aware of their needs, and suppliers' competition to satisfy those needs drives towards the best solution' (Georghiou et al., 2014; p.2); no explanation is given about how PP can contribute to the emergence and development of the market or the role of knowledge in these processes. 
Recent research on PP within innovation studies has moved away from this information-based view and emphasised the importance of knowledge and interactive learning in markets (Edler et al, 2005; Edler and Georghiou, 2007; Hommen and Rolfstam, 2008; Rolfstam, 2013). In this view, the procurement of innovations is not the result of an anonymous information-based market process (Edler et al, 2005; Rolfstam, 2013), but the result of users-producers' cooperation and knowledge-sharing processes (von Hippel, 1988; Lundvall, 1988; Chicot and Matt, 2018). This perspective conceives knowledge as fundamentally different from information (Loasby, 1999; Metcalfe, 1998; Nelson, 2000): it is partly tacit, not freely accessible, and dependent on the interactions and the (limited) cognitive and learning capacities of its holders (Metcalfe, 2005; Smith, 2000). Therefore, when procuring innovations public purchasers hold important (partly tacit) knowledge about the need or problem for which an innovative solution is to be developed that needs to be shared with potential suppliers. Public buyers may nevertheless lack the knowledge about the existence and/or characteristics of the innovative solutions that can address their needs and suppliers often fail to signal these. There is also uncertainty and risk as suppliers tend not to trust demand and may also lack the capabilities to develop or adapt the innovation to customers' needs. In general, user-producer's knowledge sharing and communication are poor and demand tends to be scattered and not sufficiently articulated for suppliers to understand users' needs and translate them into innovations (Edler and Georghiou, 2007). Rather than being information related problems, all these are issues rooted in the knowledge-related nature of the interactions between the users and suppliers of an innovation (Metcalfe, 2005, 1998). This knowledge-based perspective also considers that markets need to be created and change over time, and suggests that PP has a fundamental role throughout the whole process of market development (Edler et al, 2005).

While acknowledging the importance of knowledge and the existence of different stages in the formation of markets for innovations, this body of work does not provide an account of the 
specific ways in which PP can contribute to market formation at each one of these stages. Existing analyses tend to focus on the role of PP at the early phases of market creation, overlooking its key influence at later developmental stages (Edler et al 2005; Rolfstam, 2013). They do not consider the interrelation and dynamic feedbacks between the different market stages, and how these influence the effect that PP actions and instruments at different points of the procurement cycle can exert on the market. As indicated in the introduction, in this work we conceptually extend this work in order to address these limitations. Our conceptual elaboration of the role of PP in the formation of markets for innovation uses a definition of the market as a knowledge-based dynamic system provided by Bleda and del Rio (2013) that we outline in the next section, and also empirical information from existing case studies on PP of innovation that we present in section 4.

\section{Markets as complex evolutionary systems}

Following Bleda and del Rio (2013) we define a market for an innovation as a complex evolutionary system composed by a population of interacting ${ }^{3}$ agents (individuals or, as in the case of businesses, organizations of individuals) that carry and use knowledge and are also able to generate and acquire knowledge through learning. In this conceptualization, the market is a dynamic system that forms over a developmental trajectory in three different stages namely origination, adoption and retention (Bleda and del Rio, 2013; Dopfer and Potts, 2008). These stages are underpinned by three different knowledge related processes: the market formation process starts with one agent or group of agents who originate the new knowledge that is needed for the innovation to emerge; the market continues to develop over time as other agents adopt this knowledge, and then retain it by applying it in their activities and operations.

\footnotetext{
${ }^{3}$ Adopting a complex systemic view entails a shift of emphasis from objects and agents to relationships, and a focus primarily on the relationships and interactions between the elements of a system (Capra and Luisi, 2014).
} 
In this framework, the knowledge required for an innovation to emerge is a 'knowledge complex' or 'system' of knowledge components mainly of two types (Dopfer and Potts, 2008; Metcalfe and Ramlogan, 2005): i) object technical knowledge components embodying the technical capacities and expertise of businesses as potential innovators, and object social knowledge components involving their ability to organise themselves and to interact with others; and ii) subject cognitive and behavioural knowledge components that respectively embody the businesses' cognitive and behavioural capabilities. For instance, the knowledge that underpins a new technology as an innovation is not exclusively new 'technical' knowledge: it is a system of interrelated object and subject knowledge components that involve new technical and social capabilities for new ways of organising resources and people, and also cognitive and behavioural capabilities for the new ways of thinking and behaving concerning the new technical knowledge (c.f. Metcalfe and Ramlogan, 2005). ${ }^{4}$

A market starts its formation when this knowledge system emerges or is originated, i.e. when these different types of knowledge interconnect or fit with each other. For this interconnection to occur, a new idea or invention, conceived by an innovative agent (entrepreneur or business organization) has to be made functional, that is, communicable and accessible (Cohendet and Meyer-Krahmer, 2001) so that it can be understood, applied and used by others. Origination thus essentially involves the typical transformations that an invention must undergo so that it can be taken to the market. Continuing with our previous example, the transformations that a technical invention requires to become an innovation entail not only technical modifications, but also cognitive, behavioural and organizational changes. A new idea will become functional if all its associated technical, social, cognitive and behavioural knowledge components connect

\footnotetext{
${ }^{4}$ The structure of this new knowledge system depends on the different significance or weights of each of its knowledge components, which depend on the type of innovation that the knowledge system underlies. In the previous example, i.e. if the innovation is a new technology, it will be underpinned by a knowledge structure characterized by a significant novel technical component.
} 
and fit with each other, or in other words, are effectively coordinated (Galbraith, 1982; Metcalfe, 2005). This coordination process is known as deep coordination of knowledge (Dopfer and Potts, 2008). For deep coordination to occur, a potential innovator must possess or be able to develop a concept or managerial mental model (cognitive component) of the innovation, and the organizational routines (behavioural component) required to develop it. They must also have the relevant technical infrastructure, knowhow and expertise (technical component) to do so. Finally, they must be aware if potential users of the innovation understand, believe in, and are willing to use it in their activities and operations (social component). If all these knowledge components are not present, or they are present but do not fit, deep coordination will fail, and the new idea will remain a novelty (even possibly just a very good idea) but will not transform into an innovation. Dopfer and Potts (2008) provide an insightful example of an unsuccessful deep coordination process: "Leonardo Da Vinci had a viable concept (cognitive component) of a helicopter. He was, as an inventor, possibly ready to carry out a test run for demonstration purposes (behavioural component), but he had neither aluminium and a combustion engine (technical component) nor the means to make others believe in the viability of his idea (social component)" (ibid., p. 39).

Once the new knowledge system underpinning the innovation has been successfully originated via deep knowledge coordination, a market will continue to develop if this knowledge is 'adopted' by a population of agents (potential users). The adoption stage in the formation of a market is characterized by another knowledge coordination process known as surface coordination (Dopfer and Potts, 2008). Market surface coordination (Bleda and del Rio, 2013) takes place via the interaction between the innovator, as the carrier of the new originated knowledge structure, and its potential adopters or users, who carry their own relevant knowledge structures themselves. Both types of agents tend to hold different knowledge sets and so will display very different interactive behaviours in the market. Surface coordination, 
and the adoption process therefore mainly depends on the level of complementarity between the innovators and users' knowledge sets which will determine how easy or difficult it is for them to interact. It also greatly depends on the capacity of both types of agents to learn and coadapt, i.e. their ability to modify the structure and content of their knowledge sets to increase their complementarity so their behaviours 'fit' with each other when interacting in the market. This means that surface coordination problems in the adoption phase might arise not only as a result of a low level of complementarity between innovators and users' knowledge sets but also as the result of organizational and cognitive inertia (Hannan and Freeman, 1993; Hodgkinson, 1997; Nelson and Winter, 1982), and/or a lack of dynamic, absorptive and learning capabilities (Cohen and Levinthal, 1990; Teece et al., 1997) on the part of the both types of agents.

The last stage in the formation of the market is the retention stage. Retention takes place via another coordination process known as operational coordination by which the knowledge underpinned by the innovation, after having been adopted, is repeatedly used by agents in their activities so that it becomes 'institutionalised', i.e., susceptible to be stably replicated and used for social and economic operations (Dopfer and Potts, 2008). Operational coordination is essentially a process of information coordination, that involves the alignment of incentives, prices and quantities by which both innovative businesses and users interact when performing market transactions. In the retention phase of the formation of a market, the knowledge structure created via deep and surface coordination has become stable, and it is only its associated information sets (prices, product information, incentives etc) that change over time. Stable does not mean static as novelty, creativity and environmental changes can make this knowledge structure change at any time. Operational coordination problems hindering innovation are a consequence of information related problems (such as information asymmetries) that prevent agents from using the innovation in a sustained manner. Indeed from a theoretical point of view evolutionary market malfunctions at the retention stage can be 
considered equivalent to market failures as defined in the neoclassical approach (Bleda and del Río, 2013).

In summary, a market for an innovation will successfully develop over time if it functions 'well' through all the stages of its development. However, the well-functioning of the market is not only defined in terms of its 'dynamic efficiency' in operationally coordinating information at the retention stage, but also and more importantly in terms of its 'evolutionary efficacy' in coordinating and creating knowledge (Dopfer and Potts, 2008; Metcalfe and Ramlogan, 2005; Metcalfe, 1998; Metcalfe and Georghiou, 1998) at the origination and adoption stages (Bleda and del Río, 2013).

As previously indicated, we use this conceptualization of the market for innovations as a basis for our theoretical account of how PP can help market formation. Specifically, we provide explanations of how PP can support the development of a market by facilitating the described deep, surface and operational coordination processes, and identify the instruments and actions that can be implemented at different phases of the procurement cycle to do so. The typical phases in a PP process are (Edler et al., 2005; Edquist et al., 2015; European Commission, 2005; Edquist and Zabala-Iturriagagoitia, 2012): identification of needs; intelligence gathering and market exploration; definition of specifications; tendering, and tender evaluation and selection; and delivery of the procured innovation. To identify the PP tools and actions that can be implemented at these phases we draw upon existing work PP of innovation and on the information provided by our illustrative case studies.

\section{Illustrative case studies}

To illustrate our conceptual elaboration of how PP can facilitate market formation by supporting the three coordination processes previously described, we use examples from existing case studies on PP and innovation. As discussed in the introduction, using case data as 
illustrations allows us to bring our conceptual arguments closer to the theoretical constructs that we have used to develop these arguments, making them stronger and more persuasive. Providing concrete examples also helps to understand better how our conceptual arguments might be applied to different empirical settings (Siggelkow, 2007).

As we have already indicated, the current literature has not explicitly studied specific ways in which PP might influence the formation of markets for innovation over time. Thus, there are no empirical analyses that specifically examine how PP can support the well-functioning of market at each of its different developmental stages. The academic literature on PP and its related policy reports, however, have produced a considerable number of case studies that provide extensive empirical evidence on PP initiatives in the context of innovation. We thus tapped into this rich evidence for our analysis. In particular, we examined a total of 160 existing case studies of PP from academic articles and communications, policy reports, and relevant databases (see Appendix 1 for a list of sources). All these cases included empirical evidence of PP having impacts (both unintended and intended) on innovation. Among these cases, we first selected those that provided evidence of PP having an impact on innovation by influencing the functioning of markets. Then from those we selected only cases in which PP had been deliberately designed and strategically used to influence the market, i.e., we excluded cases in which the PP initiatives had as a primary objective the improvement of the quality of public services, and their effects on the market occurred only as a by-product. When the goal of the initiative was not reported explicitly, we inferred if from the information provided in the case. Making such inference required that this information was clear and sufficient, therefore this was an additional criterion for our selection of cases, i.e. we excluded cases in which the objective of the PP initiative could not be clearly inferred. 
Through this process we selected a total of seven case studies in which PP was strategically designed to promote the development of a specific innovation by influencing the market (see Table 1). The selected cases include the PP of a variety of technologies, products and services namely green houses, energy centres, electric vehicles, lighting systems, and the provision of organic meals. In four of them, PP aimed at the development of a new-to-the-world solution, which required the creation of a market for a completely new technology, product of service. In the remaining three, the aim was to create a market for a technology, product or service that was new for the country or region, and so innovation was required in order to adapt it to the specific national or local context. The range of end-users also varies across our case studies: in three of them, the public authorities were also end-users while in the four remaining cases procuring organisations acted on behalf of other end-users. Finally, our selected PP initiatives present different outcomes: four of them reportedly succeeded, a market was successfully formed resulting in the development and diffusion of the innovative solution, and three failed or had mitigated success (the market formation process was sluggish).

According to our objective, i.e. to use the case data for illustrative purposes, we coded the information extracted from the selected cases as follows. For each case we identified deep, surface and operational coordination problems (or lack thereof) that we considered might have affected the functioning of the market of the innovation. We listed all the PP instruments and actions reported in the cases taking into account at what phases of the procurement cycle they were implemented: identification of needs (phase 1); market exploration (phase 2); definition of specifications (phase 3); tendering, and tender evaluation and selection (phase 4); and delivery (phase 5). We added to that list additional actions and instruments proposed in the literature. ${ }^{5}$ We then grouped these instruments in categories (and sub-categories when

\footnotetext{
${ }^{5}$ We specifically drew upon the comprehensive list provided by Georghiou et al. (2014) and Chicot and Matt (2018).
} 
appropriate) according to their goal, their position/use in the procurement cycle, and the way in which they could facilitate market formation by addressing deep, surface, and operational coordination issues.

\section{The role of PP at the different stages of market formation}

\subsection{Origination - market formation stage 1}

PP can support deep coordination of knowledge at the origination stage by signalling businesses, with a new idea or invention, that potential users exist, believe in its viability, and are willing to use it, i.e., by providing businesses with the social component of the knowledge system underpinning the innovation. If the social component is not missing, PP can facilitate deep coordination by strengthening existing links or enabling the creation of links between this social component and its associated cognitive, behavioural, and technical ones.

PP may enable deep coordination in these two ways at the "definition of specifications" phase (phase 3) of the procurement cycle: by facilitating the expression of a demand (creation and strengthening of knowledge links), and by creating demand (social component provision). PP can also help strengthen and create knowledge links at this phase of the cycle by making relevant regulatory and institutional conditions more favourable for the emergence of the innovation (see Table 2 and Fig.1).

Proposition 1. PP can support deep coordination of knowledge (the origination stage of market formation) at the "definition of specifications" phase of the procurement cycle by i) providing potential innovators with the social component of the knowledge structure underpinning the innovation, and by ii) strengthening or enabling the creation of links between an existing social component and its associated cognitive, behavioural, and technical ones.

PP can facilitate the expression of a demand via two instruments: design contests (European Commission, 2009), and functional specifications in calls for tenders (Georghiou et al., 2014). Design contests are generally used in PP initiatives aimed at addressing needs for which technologies, products and services are not yet available. In a design contest, businesses that 
might potentially supply the innovative solution compete by creating a design or a plan to develop it. The designs are usually evaluated by a professional panel of experts. Contests may also allow the participation of potential users of the solution. The experts panel selects designs based on their performance at different steps of the contest process (solution design, prototype development, and testing) until one is identified as the most appropriate to meet users' needs. The interactions among experts and businesses throughout the contest contribute to deep coordination of knowledge, i.e to the emergence of the knowledge system required to develop the new solution, by increasing businesses' understanding of users' needs, and allowing them to interconnect the cognitive, behavioural, and technical capabilities to develop an innovation that can effectively address these needs.

Our case 1 (see Table 1) illustrates this. In this case, the Ministry of Agriculture, Nature and Food in the Netherlands used a design contest for the procurement of an energy-producing greenhouse that could reduce the $\mathrm{CO} 2$-emissions of the domestic horticulture sector. During the first rounds of the contest, selected manufacturers produced preliminary proposals and prototypes of greenhouses which were evaluated by an independent jury. Representatives of the horticulture industry (potential users) were involved participating and providing feedback throughout the contest. The initiative was successful and a new highly energy efficient greenhouse was developed as a result. The design contest was key for this success: the greenhouses manufacturers already possessed a viable concept of what a more efficient greenhouse in terms of $\mathrm{CO}_{2}$ emissions reduction would involve (cognitive knowledge component). They also had the knowhow and the technological expertise required to build a prototype (technical component), as well as the relevant routines, organisational processes and capabilities required to build the greenhouse and test it (behavioural component). The links between these and the social component of the knowledge underpinning the innovation were however missing, and their creation was precisely what the contest facilitated. As stated by the 
European Commission, "the development of such new technology had apparently not been taken up by the private sector on its own. The market possessed the knowhow and expertise required to assemble a total concept, but some further coordination was needed to utilise this knowledge to come up with concrete solutions" (European Commission, 2009, p. 70). The active participation of representatives of the horticulture industry in the contest also reinforced signals to manufactures that potential users believed in the viability of the new greenhouse, and that were willing to use it. In addition, the feedback and recurrent interactions between manufacturers, experts and users enhanced the communication of needs and other relevant knowledge, and guided the definition of specifications allowing manufacturers to develop a greenhouse that effectively addressed the horticulture industry's' needs.

PP can also support deep coordination by facilitating the expression of a demand using open functional specifications. In functional specifications, identified users' needs are specified as outcome-based requirements allowing potential innovators to choose how to develop the new solution as long as these requirements are fulfilled by it (Georghiou et al., 2014). Outcomebased requirements usually add clarity and accuracy in the expression of needs, and provide a high degree of flexibility in the design of the solution (Uyarra et al., 2014); this can contribute to the process of deep coordination by making it easier for potential innovators to use and interconnect their existing cognitive, behavioural, and technical knowledge capabilities to develop a solution that address these needs. Case 2 illustrates this. In this case, Svensk Växtkraft $\mathrm{AB}$, a consortium of Swedish municipalities and associations of farmers used functional specifications to procure a new type of power plant that could produce bio-energy and fertilisers based on bio-waste. The functional specifications included clear outcome-based requisites for the plant and accurately reflected users' needs, but also offered selected businesses wide scope and flexibility to choose both the plant's design and technological characteristics. Innovators could therefore use their own concept of the plant (cognitive 
component); it was also easier for them to identify and use the capabilities and routines (technological and behavioural components) required to develop a plant that effectively could address a clearly expressed set of users' needs (social component). The use of a functional call for tenders indeed was considered a key factor behind the success of the initiative (European Commission, 2010; Rolfstam, 2010, 2012). In this case, as before, all the knowledge components required to develop the new power plant were present, but the use of functional specifications in its procurement facilitated their deep coordination by creating and reinforcing their links by increasing the level of complementarity among them.

As indicated, PP can also support deep coordination and origination by creating a demand for an innovation. Public organisations can do so by committing themselves to purchasing and using the innovation, i.e. by becoming a user, and/or by encouraging others to do so (Uyarra and Flanagan, 2010). In this case PP contributes to deep coordination by providing the social component of the knowledge system underpinning the innovation. Case 3 provides an example of this type of support. In this PP initiative, the city of Stockholm in Sweden aimed at creating a local market for electric and plug-in hybrid electric vehicles. The Stockholm Environment and Health Administration encouraged both public organisations and businesses to take part in the initiative and managed to create a 'buying group' consisting of 296 organisations with all of them committing to a minimum number of purchases. The creation of this demand provided the missing social knowledge component underpinning the innovation in the new context, as it sent a strong signal to local manufacturers of electric and plug-in hybrid electric vehicles that potential users in the area believed in the new technology and were willing to use it. Our case 4, on the other hand, offers an example of how PP failed to provide this social component, which prevented deep coordination and hence market origination from occurring. The initiative in this case was part of an overall strategy to re-generate the town centre of Bracknell Forest in the UK via the procurement of a wood-chip-fuelled plant that would supply energy to two local 
energy centres. The project was cancelled after the publication of the call for tenders as no tenant committed to purchasing the energy produced by the new plant (Rolfstam, 2007, 2009, 2012). As public authorities failed to create a demand, i.e. to provide the social knowledge component required for the innovation to emerge, deep coordination failed, and this new (good) idea for an energy plant was never developed as an innovation.

Finally, PP may support the origination stage of market formation by making the regulatory framework and institutional conditions more favourable for the development of an innovation. In this case PP contributes to deep coordination by reducing the likelihood of environmental factors (external to the market) having a negative impact on a newly developed solution by destabilizing the already coordinated knowledge system underpinning it. For instance, a public authority via PP can adapt existing regulations and standards to remove potential institutional and legal obstacles regarding the use of a new product, technology or service. Our previously outlined case 2 provides an example of this type of support. In this case, public procurers facilitated the regulatory and legal processes needed to approve the use of the fertilisers produced by the energy power plant as a by-product for food production. The initiative also included commercial agreements with a local bus company regarding the supply of bio-fuel. PP can also be used to address potential problems derived from a lack of acceptance of the innovation by the public in general. In certain cases, procured innovations may have an impact on individuals, businesses and other organisations who neither supply nor use them. PP initiatives can involve these third-party actors in the procurement process so that businesses can take into account their views and develop new solutions that are more likely to be widely accepted. Again, in case 2 the procuring organisations consulted the future neighbourhood of the new bio-waste fed power plant as well as relevant environmental and consumer organisations in order to assess and gain their acceptance of the initiative. 


\subsection{Adoption -market formation stage 2}

The adoption stage in the formation of the market is underpinned by a process of surface coordination that takes place through the interactions between the innovators and the users of a newly developed innovation. As previously indicated, the success of this coordination process, and hence of the adoption market stage, depends on the degree of complementarity between both agents' knowledge sets, as well as on their ability to change these sets by processes of coadaptation and learning. PP can contribute to achieving or increasing the complementarity between the innovators and users' knowledge sets in two ways: by involving users, and/or highly experienced procurement organisations at the very early phases of the procurement cycle, and by supporting the co-adaptation and interactive learning of innovators and users at later procurement phases (see Table 2 and Fig. 1).

Proposition 2. PP can support surface coordination of knowledge (the adoption stage of market formation) by $i$ ) increasing the complementarity between the innovators and users' knowledge sets at the "identification of needs" and "market exploration and stakeholders' consultation" phases of the procurement cycle, and by ii) supporting users and suppliers' coadaptation and interactive learning at the "tendering, and tender evaluation and selection" and "delivery" procurement stages.

In order to create and express a new demand at the "definition of specifications" phase of the procurement cycle (phase 3), procuring organizations must first “identify users' needs" (phase 1). They also must determine via "intelligence gathering and market exploration" (phase 2) if existing off-the-shelf products, technologies or services can satisfy these needs, or if there are businesses that can do so by developing an innovation within a reasonable period of time. Involving users in these initial phases of the procurement cycle can help surface coordination by ensuring a good level of complementarity between the users and innovators' knowledge sets. The active participation of users in the procurement of the innovation enhances the procuring organisations' understanding of users' knowledge sets which include not only their needs but also their mental models, habits, preferences and skills. This enhanced understanding allows 
them to better identify if there are businesses that can provide an innovation, or that possess the cognitive models, technical expertise, routines and organisational capabilities (knowledge sets) required to originate one, which more effectively matches users' knowledge sets. This enables a higher degree of complementarity between the innovators and users' knowledge sets at the very early phases of the procurement cycle which is key for the coordination of their behaviour (surface coordination) later on in the market adoption stage.

It has to be noted that the involvement of users in these two initial phases of the cycle, and the ensuing better understanding of users' knowledge bases and needs, may also facilitate the expression of the demand in the "definition of specifications" procurement phase, and hence support deep coordination and origination. However, the influence of users' involvement in deep coordination is much less significant than its effect on surface coordination. An ineffective identification of users' needs, and/or an inadequate market exploration leading to a low level of complementarity between users and suppliers' knowledge sets, will not necessarily prevent deep coordination and origination from occurring: as long as users' needs are specified and communicated, the relevant knowledge components underpinning the innovation might coordinate, fit together to develop the innovation even if it will be one that fulfils 'mis-specified' users' needs. A low level of complementarity between users and innovators' knowledge sets, however, will manifest later on in their interactive behaviour causing fundamental surface coordination problems and hindering the market formation process in the adoption stage.

Our case 5 illustrates how low knowledge complementarity due to problems at the initial stages of a procurement cycle can impede later market surface coordination. In this case, the City of Ghent, Belgium, attempted to introduce via public procurement environmentally friendly vehicles in its public fleets in order to help their development and wider diffusion among the private sector. Users' needs, in relation to infrastructure required, fuel availability, and usage 
were identified and electric and compressed natural gas $(\mathrm{CNG})$ vehicles were selected as the most appropriate solution to address these needs, and the project was implemented. Public procurers managed to create a demand for the vehicles in the new local context and expressed it in the initiative's call for tenders. The initiative however only had limited success: the public sector adopted the new solution, but the technology failed to be adopted by the private sector and the local citizens. Through the lenses of our analysis this was due to surface coordination issues that were originated at the early phases of the procurement cycle. When carrying out market exploration and identifying the users' needs in the new local context, procurers failed to adequately match the potential innovators and users' knowledge sets in relation to the use, infrastructure, fuel availability and characteristics of the electric vehicles. The charging points, speed, and allowed mileage of the procured vehicles might have been appropriate for public organisations to use in a work-related context but did not match the needs, mental models, skills and habits of the public in general. In addition, it is high likely that private users were reluctant to modify their habits (due to the inertia typical in behavioural change) or/and lacked the skills to use the cars and were not willing to acquire them. i.e. to learn. Manufactures may have also lacked the learning (dynamic) capabilities to adapt the knowledge components underlying the new technology to the local private users' abilities and needs. The involvement of potential users in the identification of needs and the market exploration procurement stages could have helped to identify and address these issues. As this was not the case surface coordination problems emerged later on and prevented the technologies from being used and successfully adopted in the new local context.

Surface coordination and the adoption stage can be supported at the early phases of the procurement cycle by outsourcing the procuring process to a highly experienced centralised public organisation. Centralised procurement organisations concentrate highly skilled human capital and expertise and so they tend to be more able to effectively identify users' needs as 
well as the innovative business and solutions that may better match these needs (Albano and Sparro, 2010; Dimitri et al., 2006; Georghiou et al., 2014), i.e. they are more able to achieve a high level of complementarity between the knowledge sets of innovators and users. Our selected case 6 illustrates this. In this case, the City and State of Hamburg, Germany, used a PP initiative to procure and encourage the use of a new lighting system to support local energy management. The Agency for City Development and Environment of both the State and the city had a long and extensive experience in the procurement of innovations and also had relevant centralised know-how about this type of technology. As a result, they were able to identify the needs, skills, and habits of potential local users of the new lighting system and select a technology supplier with the organisational and dynamic capabilities to develop and adapt the system to match them, ensuring users and innovators' knowledge complementarity at the very initial phases of the procurement process.

As indicated, PP can also support surface coordination by facilitating the co-adaptation and learning of users and suppliers at later phases of the procurement cycle (see Table 2 and Fig. 1), i.e. at the "tendering, tender evaluation and selection" phase (phase 4), and the "delivery of the procured innovation" phase (phase 5). At these phases, public organisations can promote trial-and-error and experimentation by facilitating or carrying out experiments in which both innovators and users can interact and learn from each other. PP can in this way help build up “dynamic complementarities" (Klein Woolthuis et al., 2005; Malerba, 1996) between them: by allowing users to learn about the characteristics of the innovation and how to use it, and suppliers to learn about how the innovation can be adapted to better address users' needs. Case 1 illustrates how experimentation can facilitate surface coordination and the adoption stage. In this case, the selected protypes of the new greenhouse in the design contest were operated during a given period of time (six months to a year) and tested afterwards under real cultivation conditions to assess their functionality and reliability. Greenhouses' manufacturers and the 
horticulture industry were involved in the experimentation and testing of the different prototypes, actively interacting and providing feedback to each other. This allowed them to learn and co-adapt their needs and knowledge sets facilitating coordination and contributing to the success of the adoption stage.

PP can also help surface coordination at later phases of the procurement cycle by providing training and educational programmes that enable users to acquire the skills and capabilities needed for an effective use of the innovation. Case 7 illustrates this for the case of a service innovation. The City of Rome, Italy, implemented a PP initiative aimed at supporting organic agriculture and the creation of an organic food market through the procurement of publicschool meals. Procurer organizations asked school meal suppliers to provide training for teachers, and organized informational campaigns for children and their parents. In addition, the initiative incorporated compulsory canteen commissions through which pupils' parents could evaluate the food provided and give feedback. By incorporating this knowledge in their knowledge sets Roman citizens modified their behaviour and increased their consumption of organic food (Morgan and Sonnino, 2007; Sonnino, 2009) which facilitated the development of the local market.

\subsection{Retention-market formation stage 3}

The retention stage involves the operational coordination of the market agents' transactions and activities via the alignment of information, prices, and incentives. PP can contribute to this coordination process at the "delivery of the innovation" phase (phase 5) of the procurement cycle mainly by providing users with incentives and relevant information regarding the innovation. There are two categories of PP instruments that can support market operational coordination: financial and non-financial support to additional purchase, and information sharing and communication tools. 
Proposition 3. PP can support operational coordination of knowledge (the retention stage of market formation) at the "delivery" phase of the procurement cycle by providing users with i) financial and non-financial incentives and ii) relevant information about how to use the innovation.

Financial incentives in the form of direct subsidies or tax incentives can be used to lower de facto the prices of new products, technologies, or services to make them more attractive for private buyers. This contributes to operational coordination by achieving a better alignment of prices and incentives between innovators and potential users. Non-financial PP instruments can also make a newly developed solution more attractive to buyers by reducing the transaction costs associated with their purchase. This can take the form of dedicated services to potential buyers. For instance, in case 6, the Agency for City Development and Environment in Hamburg allowed additional purchasers to use the procurement agreement established with the selected supplier, saving buyers the administrative costs and transaction costs associated with the purchasing of the procured innovation. Another way of reducing transactions costs is the use of framework agreements. These were used in two of our successful cases, case 2 and 6 . Framework agreements are used in PP initiatives as mechanisms for demand aggregation. Aggregating the demand avoids the duplication of transaction costs that would result from additional individual buyers undertaking the procurement process on their own, and from competing businesses submitting distinct offers for each procurement process (Albano and Sparro, 2010). Framework agreements provide users with the information needed for the completion of the purchase procedure diminishing thus its transaction and administrative costs. They also benefit suppliers as the agreements save them from having to engage in multiple parallel transactions with several clients for the delivery of the same goods and services.

Finally, PP initiatives can support operational coordination by the inclusion of information sharing and communication tools at the deliver procurement phase. These instruments are used to address information related deficiencies arising from a lack of information on the use of the 
innovation, and to raise users' awareness of its existence and applicability. These tools contributed to the success of the initiatives in cases 2 and 6 in which websites, presentations, workshops, and networking events were used to disseminate information among potential users with the aim of capturing additional buyers.

\section{Conclusions}

In this work we have analyzed the specific ways in which PP can influence the development of markets to encourage the creation and diffusion of innovations. Existing research on PP and innovation has highlighted that markets for innovations are dynamic and that knowledge, understood as different from information, is important in this dynamics. Despite recognising that these two ideas are key to understand how PP can support innovation, this research does not provide explanations of how this supporting role of PP varies across the different (but dynamically interrelated) stages of the development of markets, and at what points of procurement cycle and via which instruments this distinctive support is more effectively exerted. Our analysis extends this research by providing a conceptual contribution that addresses these limitations. We use an evolutionary framework and define markets as dynamic systems whose main function is to create and coordinate knowledge as they form over time. We argue that the role of PP in supporting the market formation process essentially derives from the distinctive characteristics that this knowledge coordinating function has at its different developmental stages. Our analysis shows that PP instruments at different phases of the procurement cycle can be used to support coordination processes of different types (deep and surface knowledge coordination, and information coordination), occurring at different levels (the micro-level and meso-level) and at different market developmental stages.

As we have seen, at the first stage of market development, for an invention (a new idea) to become an innovation, businesses must be able to originate a knowledge system by efficaciously coordinating the technical, social, cognitive and behavioural knowledge elements 
necessary to make the new idea 'functional' and ready to use. PP can contribute to this coordination by providing the social knowledge component (when missing), and/or by reinforcing the links between these components at the definition of specifications phase of the procurement cycle. At this stage thus, PP acts by helping the deep coordination of heterogenous knowledge elements and the emergence of knowledge at the micro-level of a business organisation (or entrepreneur) as a potential innovator.

PP has also a key role at the next stage of the market formation (once deep coordination has occurred) as an enabler of the success of the interactive behaviours of innovative businesses and users by assuring a good level of complementarity between their heterogeneous knowledge sets. At this stage, PP is also facilitating the coordination of knowledge (underpinning this behaviour) but this time by acting at the meso-level of the market, i.e. by supporting the surface coordination of two heterogenous knowledge systems carried by two different micro-units. We have shown that PP can do so at the very early phases of the procurement cycle: how complementary and how well or efficaciously the knowledge sets of users and suppliers are aligned at these phases will greatly determine their behaviours and the success of the adoption market stage at a later time (see Fig. 1). By highlighting the interrelation between the dynamics of market formation and the phases of the procurement cycle, we bring attention to the need of considering the influence that the very early phases of the procurement of an innovation can have for its future adoption and diffusion. Even if surface coordination issues affecting the market adoption stage might seem far away in time at the initial phases of the procurement cycle, it is precisely at these phases where these issues might be addressed. This has important conceptual implications to understanding the role of PP as an innovation policy tool as it places PP within a more long-term and less myopic dynamic framework, and emphasises the need to account for the role of knowledge systems and learning capabilities of users and suppliers from the very beginning of the procurement process. 
PP can also support the final stage of the development of markets (once that surface coordination at the adoption stage has taken place). As we have shown, PP at the end of the procurement cycle can facilitate the interactive behaviour between users and innovation suppliers by contributing to the coordination of information and the alignment of incentives between both types of agents. The role of PP as a facilitator of operational coordination is important since, even if an innovation has been successfully developed (deep coordination has occurred), and is being adopted (surface coordination has occurred), misaligned incentives and information asymmetries between innovators and users can affect the development of the market by significantly hindering the wider use and diffusion of the innovation. The incorporation of financial and non-financial incentives, as well as relevant information in PP initiatives can help to fix misalignment and reduce information asymmetries increasing market efficiency at its final stages of development. Our work also highlights that to understand how PP can effectively help the market development process, it is necessary to consider the dynamic nature of knowledge and the implications of this for the interrelation and feedbacks between the different stages of this process. Agents in our analysis are carriers of knowledge, and are also able to modify this knowledge by learning. This means that their knowledge systems are dynamic; they change as the market develops over time. Changes in the users and suppliers' knowledge systems can be originated endogenously, i.e. can be rooted in changes in users' tastes and preferences, their habits, skills, and/or can be originated by changes in the cognitive, behavioural, and technical capabilities of suppliers. Factors exogenous to the agents, such as technological advances, and changes in legislation and the institutional environment can also cause modifications their knowledge systems.

Changes taking place during the adoption stage of the market formation process will break existing structural links among the elements of knowledge systems previously created at the origination stage. The market will only continue to develop if a new process of deep 
coordination leading to the emergence of a new knowledge system underpinning the innovation takes place. Similarly, adoption will require renewed surface coordination and the adaptation via learning of the users and suppliers' knowledge systems. Once the innovation is stable in this new setting, new information including prices, and incentives will need to be provided to ensure the viability of the renewed market. In summary, any novelty arising within the market or from the environment that disturbs the market at one given stage will have an effect on the other stages. This has fundamental implications for the effectiveness of PP in supporting the different stages of market development. In particular, in the face of the aforementioned changes, identifying and assessing the learning (dynamic) capabilities of both users and innovative businesses becomes fundamental for the origination and adoption stages: the success of PP in encouraging the formation of markets for innovation is intrinsically linked to the capacity of market actors, on the supply and demand sides, to adapt their respective knowledge systems (hence their interactive behaviour) in changing knowledge contexts. The interaction between different developmental market stages will also influence the effectiveness of PP at the last stages of market formation. Specifically, PP support for operational coordination will only be effective as long as the knowledge systems coordinated at previous stages remain stationary. If as a result of novelty new knowledge systems have been created via deep and surface coordination, using PP information and incentive related tools without considering these changes will prove a waste of policy resources and efforts as these will be addressing operational problems that are underpinned by 'old' knowledge structures. Any PP intervention at the later stages of the procurement cycle will only have a positive influence on the outcomes of a specific 'already coordinated' knowledge structure. If exogenously or endogenously generated novelty changes or ruptures this structure, PP must focus on supporting the newly required deep and/or surface coordination processes rather than on any operational intervention. By providing a better understanding of how PP can affect the dynamics of market development 
our work contributes to a more effective PP design and implementation. Conceptually robust theoretical analyses can help shape actual policy making decisions by signalling situations in need of government intervention and by offering guidelines for the effective use of specific policy instruments and actions (Laranja et al., 2008; Nelson, 2009).

As an initial and previously unexplored attempt, our contribution presents limitations which at the same time offer the opportunity for further exploration and conceptual elaborations on how PP can be used to influence markets and encourage innovation. For instance, our focus has been on the knowledge related coordination processes and interactions that take place at the micro level of the innovating business organizations, and among micro-agents at the mesolevel of the market. For the sake of simplicity, we have not included all factors affecting the internal coordination and behavioural dynamics within business organisations. We have also 'blackboxed' the interactions and coordination process taking place at the lower level of the individuals within both users and procuring organizations. The latter is particularly relevant in the context of PP since as it has been highlighted in the literature (Georghiou et al., 2014; Rolfstam, 2009, 2013) that coordination problems within procuring organisations can be highly detrimental to the success of PP of innovation initiatives. A natural next step for our research is then to incorporate the influence of these processes of internal coordination in the analysis. In addition, we have used existing selected case studies exclusively for illustrative purposes. An additional next step is therefore the empirical testing and validation of our theoretical contribution. 


\section{References:}

Albano, G.L., Sparro, M., 2010. Flexible Strategies for Centralized Public Procurement. Review of Economics and Institutions 1. https://doi.org/10.5020/rei.v1i2.4.

Arrow, K., 1962. Economic Welfare and the Allocation of Resources for Invention, in: The Rate and Direction of Inventive Activity: Economic and Social Factors. Princeton University Press, Princeton, pp. 609-626.

Aspers, P., 2011. Markets. Polity Press, Cambridge.

Bleda, M., del Río, P., 2013. The market failure and the systemic failure rationales in technological innovation systems. Research Policy 42, 1039-1052. https://doi.org/10.1016/j.respol.2013.02.008.

Brammer, S., Walker, H., 2011. Sustainable procurement in the public sector: an international comparative study. International Journal of Operations \& Production Management 31, 452-476. https://doi.org/10.1108/01443571111119551.

Buzzell, R.D., 1999. Market Functions and Market Evolution. Journal of Marketing 63, 61. https://doi.org/10.2307/1252101.

Capra, F., Luisi, P.L., 2014. The systems view of life: a unifying vision. Cambridge University Press, Cambridge.

Chicot, J., Matt, M., 2018. Public Procurement of Innovation: A Review of Rationales, Designs, and Contributions to Grand Challenges. Science and Public Policy 45, 480-492. https://doi.org/10.1093/scipol/scy012.

Clement, S., Evans, N., Chandler, C., Wiesinger, P., Robb, A., Hosking, E., Koch, H., Sunnerstedt, E., Anastase, D., Kury, C., Gilbert, M., Helsloot, L., Uhan, M., Babb, W., 2015. Clean fleets case studies. Clean Fleets.

Cohen, W.M., Levinthal, D.A., 1990. Absorptive Capacity: A New Perspective on Learning and Innovation. Administrative Science Quarterly 35, 128-152. https://doi.org/10.2307/2393553.

Cohendet, P., Meyer-Krahmer, F., 2001. The theoretical and policy implications of knowledge codification. Research Policy 30, 1563-1591. https://doi.org/10.1016/S00487333(01)00168-8.

Dimitri, N., Dini, F., Piga, G., 2006. When should procurement be centralized?, in: Dimitri, N., Piga, G., Spagnolo, G. (Eds.), Handbook of Procurement. Cambridge University Press, Cambridge.

Dopfer, K., Potts, J., 2008. The General Theory of Economic Evolution. Routledge, London; New York.

Dosi, G., 1988. The Nature of the Innovative Process, in: Technical Change and Economic Theory. Pinter, London, the United Kingdom.

Droste, N., Hansjürgens, B., Kuikman, P., Otter, N., Antikainen, R., Leskinen, P., Pitkänen, K., Saikku, L., Loiseau, E., Thomsen, M., 2016. Steering innovations towards a green economy: Understanding government intervention. Journal of Cleaner Production 135, 426-434. https://doi.org/10.1016/j.jclepro.2016.06.123.

Edler, J., Georghiou, L., 2007. Public procurement and innovation - Resurrecting the demand side. Research Policy 36, 949-963. https://doi.org/10.1016/j.respol.2007.03.003.

Edler, J., Ruhland, S., Hafner, S., Rigby, J., Georghiou, L., Hommen, L., Rolfstam, M., Edquist, C., Tsipouri, L., Papadakou, M., 2005. Innovation and Public Procurement. Review of 
Issues at Stake, Study for the European Commission. Fraunhofer Institute Systems and Innovation Research, Karlsruhe.

Edquist, C., Vonortas, N.S., Zabala-Iturriagagoitia, J.M., Edler, J. (Eds.), 2015. Public Procurement for Innovation. Edward Elgar, Cheltenham.

Edquist, C., Zabala-Iturriagagoitia, J.M., 2012. Public Procurement for Innovation as missionoriented innovation policy. Research Policy 41, 1757-1769. https://doi.org/10.1016/j.respol.2012.04.022.

European Commission, 2010a. Risk management in the procurement of innovation - Concepts and empirical evidence in the European Union (Expert Group Report). Publications Office of the European Union, Luxembourg.

European Commission, 2010b. Green Public Procurement: A collection of good practices.

European Commission, 2009. Exploring public procurement as a strategic innovation policy instrument (EU Project OMC-PTP). European Commission, Berlin.

European Commission, 2007. Guide on dealing with innovative solutions in public procurement: 10 elements of good practice (PRO INNO Europe paper). Publications Office of the European Union, Luxembourg.

European Commission, 2005. Public Procurement for Research and Innovation: Developing Procurement Practices Favourable to R\&D and Innovation (Expert Group Report). Publications Office of the European Union, Luxembourg.

Galbraith, J.R., 1982. Designing the innovating organization. Organizational Dynamics 10, 525. https://doi.org/10.1016/0090-2616(82)90033-X.

Georghiou, L., Edler, J., Uyarra, E., Yeow, J., 2014. Policy instruments for public procurement of innovation: Choice, design and assessment. Technological Forecasting and Social Change 86, 1-12. https://doi.org/10.1016/j.techfore.2013.09.018.

Geroski, P.A., 1990. Procurement policy as a tool of industrial policy. International Review of Applied Economics 4, 182-198. https://doi.org/10.1080/758523673.

Hannan, M.T., Freeman, J., 1993. Organizational ecology, Harvard Univ. Press, Cambridge.

Hodgkinson, G.P., 1997. Cognitive Inertia in a Turbulent Market: the Case of UK Residential Estate Agents. Journal of Management Studies 34, 921-945. https://doi.org/10.1111/1467-6486.00078.

Hommen, L., Rolfstam, M., 2008. Public Procurement and Innovation: Towards a Taxonomy. Journal of Public Procurement 8, 17-56. https://doi.org/10.1108/JOPP-08-03-2008B001.

Hviid, M., Price, C.W., 2014. Well-Functioning Markets in Retail Energy. European Competition Journal 10, 167-179. https://doi.org/10.5235/17441056.10.1.167.

Klein Woolthuis, R., Lankhuizen, M., Gilsing, V., 2005. A system failure framework for innovation policy design. Technovation 25, 609-619. https://doi.org/10.1016/j.technovation.2003.11.002.

Laranja, M., Uyarra, E., Flanagan, K., 2008. Policies for science, technology and innovation: Translating rationales into regional policies in a multi-level setting. Research Policy 37, 823-835. https://doi.org/10.1016/j.respol.2008.03.006.

Loasby, B.J., 1999. Knowledge, institutions, and evolution in economics. Routledge, London.

Lundvall, B.-A., 1988. Innovation as an interactive process: from user-producer interaction to the national system of innovation, in: Dosi, G., Freeman, C., Nelson, R., Silverberg, G., Soete, L. (Eds.), Technical Change and Economic Theory. Pinter Publishers, London. 
Malerba, F., 1996. Public Policy and Industrial Dynamics: an Evolutionary Perspective, in: Edquist, C. (Ed.), The Innovation Systems and European Integration (ISE) Final Report. Linköping.

Mele, C., Pels, J., Storbacka, K., 2015. A holistic market conceptualization. Journal of the Academy of Marketing Science 43, 100-114. https://doi.org/10.1007/s11747-0140383-8.

Metcalfe, J.S., 2005. Systems Failure and the Case for Innovation Policy, in: Llerena, P., Matt, M. (Eds.), Innovation Policy in a Knowledge-Base Economy. Springer, Berlin.

Metcalfe, J.S., 1998. Evolutionary economics and creative destruction. Routledge, London.

Metcalfe, J.S., Ramlogan, R., 2005. Limits to the economy of knowledge and knowledge of the economy. Futures, Complexity and the limits of knowledge 37, 655-674. https://doi.org/10.1016/j.futures.2004.11.006.

Metcalfe, S., Georghiou, L., 1998. Equilibrium and evolutionary foundations of technology policy. STI Review 22, 75-100.

Morgan, K., Sonnino, R., 2007. Empowering consumers: the creative procurement of school meals in Italy and the UK. International Journal of Consumer Studies 31, 19-25. https://doi.org/10.1111/j.1470-6431.2006.00552.x.

Nelson, R.R., 2009. Building Effective 'Innovation Systems' versus Dealing with 'Market Failures' as Ways of Thinking About Technology Policy, in: The New Economics of Technology Policy. Edward Elgar, Cheltenham.

Nelson, R.R., 2000. On the complexities and limitations of market organizations. Mimeo.

Nelson, R.R., 1959. The Simple Economics of Basic Scientific Research. Journal of Political Economy 67, 297-306. http://dx.doi.org/10.1086/258177.

Nelson, R.R., Winter, S.G., 1982. An Evolutionary Theory of Economic Change. Harvard University Press, Cambridge.

OECD, Eurostat, 2005. Oslo Manual: Guidelines for collecting and interpreting innovation data, Third edition. ed, The Measurement of Scientific and Technological Activities. OECD Publishing, Paris.

Potts, J., 2001. Knowledge and markets. Journal of Evolutionary Economics 11, 413-431. https://doi.org/10.1007/PL00003865.

Rolfstam, M., 2013. Public Procurement and Innovation: The Role of Institutions. Edward Elgar, Northampton.

Rolfstam, M., 2012. Public procurement of innovation: demand as in command or facilitation of endogenous knowledge conversion? Presented at the Conference on Demand, Innovation and Policy: Underpinning Policy Trends with Academic Analysis, Manchester.

Rolfstam, M., 2010. Early involvement of stakeholders in Public Procurement of Innovation. The Case of The Biogas and Upgrading Plant. Presented at the 19th Annual International Purchasing and Supply Education and Research Association (IPSERA) Conference, Lappeenranta.

Rolfstam, M., 2009. Public procurement as an innovation policy tool: the role of institutions. Science and Public Policy 36, 349-360. https://doi.org/10.3152/030234209X442025.

Rolfstam, M., 2007. Organisations and Institutions in Public Procurement of Innovations: The Case of the Energy Centre in Bracknell, UK. Presented at the DRUID-DIME Academy Winter $2007 \mathrm{PhD}$ Conference on Geography, Innovation and Industrial Dynamics, Aalborg. 
Rothwell, R., 1984. Creating a Regional Innovation-oriented Infrastructure: The role of public procurement. Annals of Public \& Co-operative Economy 55, 159-172.

Saussier, S., Tirole, J., 2015. Strengthening the Efficiency of Public Procurement (Les notes du Conseil d'analyse économique No. 22). Conseil d'analyse économique, Paris.

Siggelkow, N., 2007. Persuasion with Case Studies. Academy of Management Journal 50, 20 24. https://doi.org/10.5465/AMJ.2007.24160882.

Smith, K., 2000. Innovation as a Systemic Phenomenon: Rethinking the Role of Policy. Enterprise \& Innovation Management Studies 1, 73-102. https://doi.org/10.1080/146324400363536.

Smith, K., 1996. Systems Approach to Innovation: Some Policy Issues, in: The Innovation Systems and European Integration (ISE) Final Report. Linköping.

Sonnino, R., 2009. Quality food, public procurement, and sustainable development: the school meal revolution in Rome. Environment and Planning A 41, 425-440. https://doi.org/10.1068/a40112.

Teece, D.J., Pisano, G., Shuen, A., 1997. Dynamic capabilities and strategic management. Strategic Management Journal 18, 509-533. https://doi.org/10.1002/(SICI)10970266(199708)18:7<509::AID-SMJ882>3.0.CO;2-Z

Tsipouri, L., 2015. Public Procurement of Innovation (Policy Brief No. 2), Innovation for Growth - i4g. European Commission.

Uyarra, E., Edler, J., Garcia-Estevez, J., Georghiou, L., Yeow, J., 2014. Barriers to innovation through public procurement: A supplier perspective. Technovation 34, 631-645. https://doi.org/10.1016/j.technovation.2014.04.003.

Uyarra, E., Flanagan, K., 2010. Understanding the Innovation Impacts of Public Procurement. European Planning Studies 18, 123-143. https://doi.org/10.1080/09654310903343567.

Vargo, S.L., Koskela-Huotari, K., Baron, S., Edvardsson, B., Reynoso, J., Colurcio, M., 2017. A systems perspective on markets - Toward a research agenda. Journal of Business Research 79, 260-268. https://doi.org/10.1016/j.jbusres.2017.03.011.

von Hippel, E., 1988. The Sources of Innovation. Oxford University Press, Oxford.

Yin, R.K., 2011. Qualitative research from start to finish. Guilford Press, New York. 


\begin{tabular}{|c|c|c|c|c|c|c|}
\hline Case & Public procurer & $\begin{array}{l}\text { Innovation: } \\
\text { Product/ technology/ } \\
\text { service }\end{array}$ & $\begin{array}{l}\text { Radically } \\
\text { new } \\
\text { solution } \\
\end{array}$ & $\begin{array}{l}\text { Public } \\
\text { procurer } \\
\text { is a user }\end{array}$ & Result & Sources \\
\hline 1 & $\begin{array}{l}\text { Ministry of Agriculture, } \\
\text { Nature \&Food Quality (The } \\
\text { Netherlands) }\end{array}$ & $\begin{array}{l}\text { Cleaner energy producing } \\
\text { greenhouses }\end{array}$ & Yes & No & Success & EC (2009) \\
\hline 2 & $\begin{array}{l}\text { Svensk Växtkraft AB } \\
\text { (Sweden) }\end{array}$ & $\begin{array}{l}\text { Renewable energy plant } \\
\text { producing bio-fertilizers }\end{array}$ & Yes & No & Success & $\begin{array}{l}\text { EC (2010); } \\
\text { Rolfstam (2010, } \\
\text { 2012) }\end{array}$ \\
\hline 3 & $\begin{array}{l}\text { Stockholm Environment and } \\
\text { Health Administration } \\
\text { (Sweden) }\end{array}$ & $\begin{array}{l}\text { Electric and Plug-in } \\
\text { Hybrid vehicles }\end{array}$ & No & Yes & $\begin{array}{l}\text { Mitigated } \\
\text { success }\end{array}$ & $\begin{array}{l}\text { Clement et al } \\
(2015)\end{array}$ \\
\hline 4 & $\begin{array}{l}\text { Bracknell Forest Borough } \\
\text { Council(United Kingdom) }\end{array}$ & Renewable energy centre & Yes & No & Failure & $\begin{array}{l}\text { Rofstam (2007, } \\
\text { 2009, 2012) }\end{array}$ \\
\hline 5 & $\begin{array}{l}\text { City of Ghent } \\
\text { (Belgium) }\end{array}$ & $\begin{array}{l}\text { Electric and Compressed } \\
\text { Natural Gas vehicles }\end{array}$ & No & Yes & $\begin{array}{l}\text { Mitigated } \\
\text { success }\end{array}$ & $\begin{array}{l}\text { Clement et al } \\
(2015)\end{array}$ \\
\hline 6 & $\begin{array}{l}\text { State and City of Hamburg } \\
\text { (Germany) }\end{array}$ & $\begin{array}{l}\text { Energy-efficient lighting } \\
\text { system }\end{array}$ & Yes & Yes & Success & Edler et al., (2005) \\
\hline 7 & City of Rome (Italy) & $\begin{array}{l}\text { Organic public-school } \\
\text { meals }\end{array}$ & No & No & Success & $\begin{array}{l}\text { EC/PP Practice; } \\
\text { Morgan \& } \\
\text { Sonnino (2007); } \\
\text { Sonnino (2009) }\end{array}$ \\
\hline
\end{tabular}

Table 1 . Summary of illustrative cases

\begin{tabular}{|c|c|c|c|}
\hline $\begin{array}{c}\text { Market } \\
\text { formation stage }\end{array}$ & $\begin{array}{l}\text { Contribution to } \\
\text { coordination }\end{array}$ & PP instruments/actions & Procurement cycle phase \\
\hline \multirow{3}{*}{$\begin{array}{l}\text { Origination } \\
\text { (Deep } \\
\text { coordination) }\end{array}$} & $\begin{array}{l}\text { Facilitating the } \\
\text { expression of a new } \\
\text { demand }\end{array}$ & $\begin{array}{l}\text { - Design contests } \\
\text { - Functional specifications }\end{array}$ & \multirow{3}{*}{$\begin{array}{l}\text { Phase 3. Definition of } \\
\text { specifications }\end{array}$} \\
\hline & Creating a demand & Commitment to purchase & \\
\hline & $\begin{array}{l}\text { Improving the } \\
\text { innovation } \\
\text { environment }\end{array}$ & $\begin{array}{l}\text { - Changes in norms, standards, rules } \\
\text { - Contribution to social acceptance }\end{array}$ & \\
\hline \multirow{4}{*}{$\begin{array}{l}\text { Adoption } \\
\text { (Surface } \\
\text { coordination) }\end{array}$} & \multirow{2}{*}{$\begin{array}{l}\text { Enhancing } \\
\text { complementary } \\
\text { between suppliers' and } \\
\text { users' knowledge bases }\end{array}$} & Users involvement & \multirow{2}{*}{$\begin{array}{l}\text { Phase } 1 \text {. Identification of } \\
\text { users' needs } \\
\text { Phase 2. Market } \\
\text { exploration and } \\
\text { stakeholders' consultation }\end{array}$} \\
\hline & & $\begin{array}{l}\text { Outsourcing the public procurement } \\
\text { process to a central organisation* }\end{array}$ & \\
\hline & \multirow[t]{2}{*}{$\begin{array}{l}\text { Facilitating suppliers } \\
\text { and users' co-adaptation } \\
\text { and interactive learning }\end{array}$} & Experimentation and testing & $\begin{array}{l}\text { Phase } 4 . \text { Tendering, and } \\
\text { tender evaluation and } \\
\text { selection }\end{array}$ \\
\hline & & Knowledge provision & \multirow{4}{*}{$\begin{array}{l}\text { Phase } 5 . \text { Delivery of the } \\
\text { procured innovation }\end{array}$} \\
\hline \multirow{3}{*}{$\begin{array}{c}\text { Retention } \\
\text { (Operational } \\
\text { coordination) }\end{array}$} & \multirow{3}{*}{$\begin{array}{l}\text { Providing information } \\
\text { and incentives }\end{array}$} & Financial support & \\
\hline & & Non-financial support & \\
\hline & & $\begin{array}{l}\text { Information sharing and } \\
\text { communication tools }\end{array}$ & \\
\hline
\end{tabular}

Table 2. Public procurement support for the formation of a market for innovation 


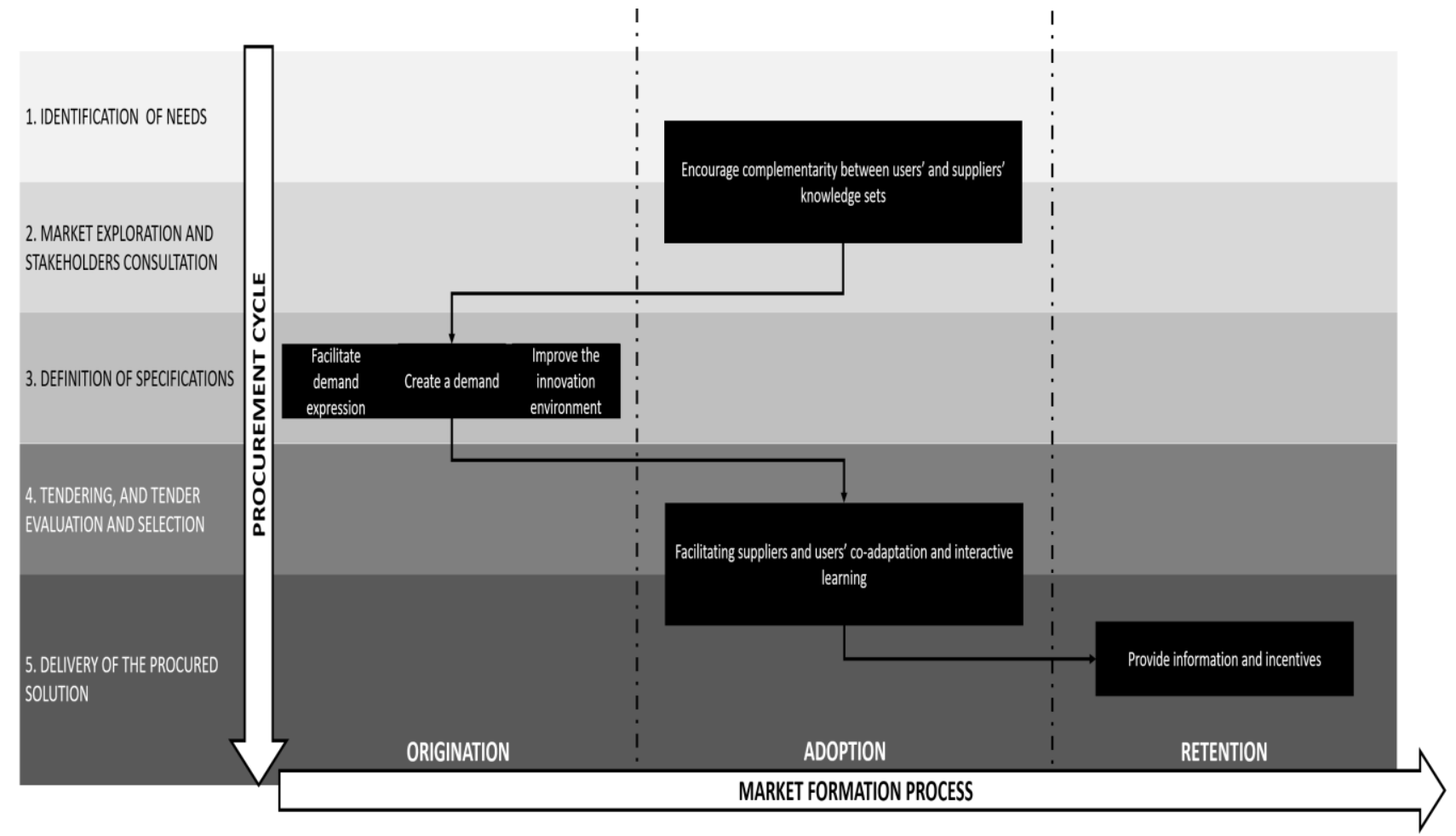

Figure 1. Public procurement support for the formation of a market for innovation 